\title{
Modelling of rheological behaviour of pummelo juice concentrates using master-curve
}

\begin{abstract}
The rheological behaviour of freeze-dried-concentrated pummelo juice was modelled to investigate the effects of temperature and concentration on its fluid type and viscosity using a rotational viscometer at shear rates ranging from 1 to $400 \mathrm{~s}-1$. The effect of concentration measured by its total soluble solids content resulted in the juice concentrates behaving towards shear thinning or pseudoplastic behaviour with flow behaviour index values, $\mathrm{n}<1$. Temperature increase from 6 to $75^{\circ} \mathrm{C}$ produced a reversing effect of the shear thinning behaviour from the increase of $n$ values at all three investigated concentrations, 20, 30 and $50^{\circ}$ Brix. The consistency coefficient decreases with temperature but increases with total soluble solid contents. Modelling the rheological behaviour of pummelo juice concentrates using the master-curve yielded results over a range of temperature to overlap on a single line, which allows generalisation of flow behaviour and characteristics. The master-curve plots confirmed that the juice viscosity and pseudoplasticity increase with concentration with high regression coefficients, R2>0.98.
\end{abstract}

Keyword: Rheological model; Master-curve; Modelling; Pummelo juice concentrate; Power law 